\title{
A study of aqueous and serum levels of ceftazidime following subconjunctival administration
}

\author{
D B CLEMENTS' AND V TAILOR²
}

From 'Whiston Hospital, Prescot, and 'Glaxo Laboratories Ltd

SUMMARY Patients undergoing cataract surgery may develop an infective endophthalmitis postoperatively which may result in the loss of an eye. This study was carried out to measure aqueous humour levels and to assess patients' tolerance of ceftazidime, a potent antipseudomonal cephalosporin, given subconjunctivally. Eighteen patients received $125 \mathrm{mg}$ ceftazidime subconjunctivally before they underwent routine cataract surgery. A further two patients received $62 \cdot 5$ mg subconjunctivally. The results show good penetration into the aqueous humour well above the minimum inhibitory concentrations (MICs) of possible pathogens. There were no postoperative infections, no local irritation, and no systemic side effects.

Ceftazidime (Fortum) is a third generation, parenteral cephalosporin, which is active against a wide range of Gram-positive and Gram-negative organisms, including pseudomonas. ${ }^{1-3}$ It is a bactericidal antibiotic, which is stable in the presence of $\beta$-lactamases.

Previous studies have shown that after intravenous administration adequate levels are achieved in the human eye to eradicate the majority of organisms found in ophthalmic infections. ${ }^{\text {th }}$ However, improved penetration could be achieved at the site of infection by administering the drug subconjunctivally. Studies measuring the ocular penetration of ceftazidime in humans following subconjunctival injections have not so far been published.

\section{Materials and methods}

Before the start of the study approval from the hospital's ethical committee was obtained. Patients who had given their informed consent received a preoperative subconjunctival injection of ceftazidime at varying time intervals before undergoing routine cataract surgery. Patients with a past history of hypersensitivity to penicillins or the cephalosporins were excluded from the trial. Preoperative investigations of all patients included serum creatinine and haemoglobin levels.

The ceftazidime solution was reconstituted by

Correspondence to D B Clements, FRCS, Whiston Hospital, Prescot, Merseyside L35 5DR. mixing $250 \mathrm{mg}$ of ceftazidime powder with $1 \mathrm{ml}$ of sterile water for injection. The freshly prepared solution had a volume of $1.2 \mathrm{ml}$. The 18 patients who received $125 \mathrm{mg}$ of ceftazidime were given $0.6 \mathrm{ml}$ of the solution, while the two patients who received a dose of $62.5 \mathrm{mg}$ ceftazidime were given $0.3 \mathrm{ml}$ of solution subconjunctivally. The operations were carried out under local or general anaesthesia.

In the course of the operation $10 \mathrm{ml}$ of blood was first withdrawn from the cubital vein. At the same time the aqueous humour was aspirated with a fine 27 gauge needle attached to a $1 \mathrm{ml}$ insulin syringe. Penetration of the eye was at the limbus in the temporal position. The aqueous humour sample was placed in a small bottle. At this stage a section was made at the limbus with a diamond knife in order to remove the cataract.

Storage of all samples was at $-70^{\circ} \mathrm{C}$. Blood samples were first clotted and only the serum was stored. Sample assays were carried out by high performance liquid chromatography.

\section{Results}

Ceftazidime levels obtained in the aqueous humour and serum of all the patients entered in the trial are shown in Table 1. One patient (patient G) had a ceftazidime level of $1.08 \mu \mathrm{g} / \mathrm{ml}$ in the aqueous humour $14 \frac{1}{2}$ hours after his subconjunctival dose. The remaining patients underwent surgery 37 minutes to 4 hours after receiving the ceftazidime dose. The aqueous humour levels ranged from $17 \cdot 3$ 
Table 1 Aqueous and serum levels following subconjunctival injections of $125 \mathrm{mg}$ ceftazidime

\begin{tabular}{|c|c|c|c|}
\hline \multirow[t]{2}{*}{ Patients } & \multirow{2}{*}{$\begin{array}{l}\text { Post injection } \\
\text { Sample time } \\
\text { (hrand min) }\end{array}$} & \multicolumn{2}{|c|}{ Ceftazidime concentration $(\mu \mathrm{g} / \mathrm{ml})$} \\
\hline & & Aqueous humour & Serum \\
\hline A & 0.37 & $77 \cdot 12$ & $1 \cdot 47$ \\
\hline B & $1 \cdot 14$ & $194 \cdot 57$ & $6 \cdot 20$ \\
\hline $\mathrm{C}$ & $2 \cdot 08$ & $97 \cdot 06$ & $5 \cdot 90$ \\
\hline $\mathrm{D}$ & $0 \cdot 14$ & $153 \cdot 6()$ & $3 \cdot 30$ \\
\hline $\mathrm{E}$ & $0 \cdot 16$ & $164 \cdot 00$ & $3 \cdot 80$ \\
\hline $\mathbf{F}$ & $1 \cdot 05$ & $38 \cdot 60$ & $3 \cdot 00$ \\
\hline G & $14 \cdot 30$ & 1.08 & $0 \cdot 16$ \\
\hline $\mathrm{H}$ & $1 \cdot 45$ & $310 \cdot 40$ & $4 \cdot 60$ \\
\hline I & $3 \cdot 12$ & $198 \cdot 54$ & $4 \cdot 21$ \\
\hline $\mathbf{J}$ & $2 \cdot 24$ & $87 \cdot 80$ & $4 \cdot 10$ \\
\hline $\mathrm{K}$ & $1 \cdot 05$ & $17 \cdot 30$ & $8 \cdot() 0$ \\
\hline $\mathrm{L}$ & $2 \cdot 00$ & $200 \cdot 30$ & $2 \cdot 30$ \\
\hline $\mathbf{M}$ & $3 \cdot 22$ & $35 \cdot 50$ & $4 \cdot 70$ \\
\hline $\mathrm{N}$ & $2 \cdot 16$ & $57 \cdot 40$ & $4 \cdot 90$ \\
\hline $\mathrm{O}$ & $4 \cdot 00$ & $85 \cdot 00$ & $3 \cdot 10$ \\
\hline$P$ & $3 \cdot 10$ & $157 \cdot 90$ & $3 \cdot 30$ \\
\hline $\mathrm{Q}$ & $1 \cdot 20$ & $120 \cdot 60$ & $3 \cdot 80$ \\
\hline $\mathrm{R}$ & $2 \cdot 08$ & $45 \cdot 20$ & $2 \cdot 10$ \\
\hline \multicolumn{4}{|c|}{ Injections of $62.5 \mathrm{mg}$ ceftazidime } \\
\hline $\mathrm{S}$ & $3 \cdot 27$ & $15 \cdot 56$ & $1 \cdot 27$ \\
\hline $\mathrm{T}$ & $1 \cdot 31$ & $24 \cdot 14$ & $1 \cdot 56$ \\
\hline
\end{tabular}

Patients G, S, and T are not shown in Fig. 1 .

to $310.4 \mu \mathrm{g} / \mathrm{ml}$. These levels are all well above the MICs required for organisms generally isolated after routine cataract surgery (see Discussion).

As expected, the serum levels were much lower than the aqueous humour levels, ranging from 1.47 to $8.00 \mu \mathrm{g} / \mathrm{ml}$. Nevertheless, these serum levels were still above the MICs for most Gram-negative bacteria.

The aqueous humour levels of ceftazidime are illustrated in Fig. 1, which shows that high levels persisted in the aqueous humour for several hours after the initial subconjunctival injection. It also shows a wide variation in the aqueous humour levels measured in the samples collected (see Discussion).

\section{Discussion}

Several investigators have measured the penetration of ceftazidime in the aqueous humour following parenteral administration. ${ }^{+h}$ Walstad and Blika ${ }^{4}$ found ceftazidime levels ranging from 11.() (SD 3.9) to 5.5 (SD 2.7$) \mu \mathrm{g} / \mathrm{ml}$ at $1 / 2$ and 5 hours respectively in the aqueous humour following a $2 \mathrm{~g}$ intravenous dose.

Axelrod et al. ${ }^{5}$ measured mean aqueous humour concentrations of $2 \cdot 80,4 \cdot 00,3 \cdot 20,3 \cdot 39$, and $1 \cdot 94$ $\mu \mathrm{g} / \mathrm{ml}$ after $1 / 2,1,2,4$, and 6 hours respectively, following a $2 \mathrm{~g}$ intravenous dose. Giamarellou et al. ${ }^{6}$ gave three $1 \mathrm{~g}$ doses of ceftazidime by intramuscular injections, and found aqueous humour levels of 1.3 $\mu \mathrm{g} / \mathrm{ml}$ and $3 \cdot 2 \mu \mathrm{g} / \mathrm{ml} 2$ and 6 hours respectively after the last dose.

The results of the present study show that considerably higher aqueous humour levels are achieved when ceftazidime is administered subconjunctivally (see Table 1). As can be seen in Fig. 1, there is a wide variation in the aqueous humour levels of ceftazidime. This is probably related to the fact that the pharmacokinetics of drugs following subconjunctival injection are very complex. ${ }^{7}$ After subconjunctival injection of ceftazidime two routes of intraocular penetration are possible ${ }^{\times}$: (1) leakage from the bleb through the needle track into the tear film; (2) direct penetration.

After penetration through the sclera the drug may enter the eye by a number of routes: (1) sideways into
Fig. 1 Ceftazidime concentration in aqueous humour $(\mu \mathrm{g} / \mathrm{ml})$ versus time after injection (hours) of 125 mg subconjunctival ceftazidime. Patients $G, S$, and T are omitted.

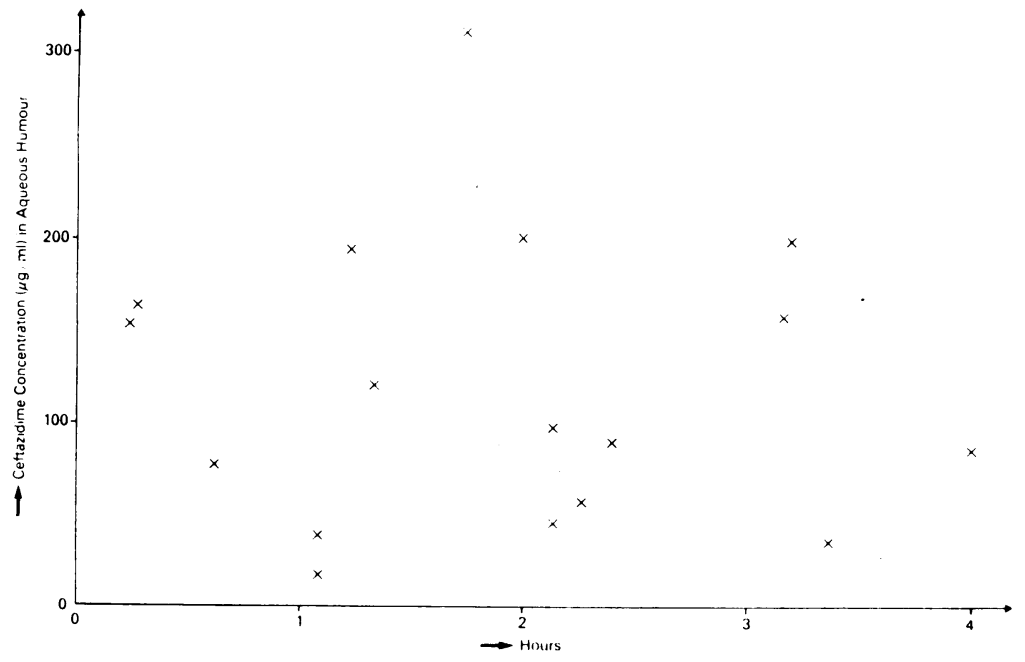


the cornea and across the corneal endothelium; (2) across the trabecular meshwork; (3) through the iris and across its anterior surface; (4) into the ciliary body and thus into the aqueous humour. The exact level of ceftazidime at any one time depends on the inflow by the above routes and also the outflow, principally through the canal of Schlemm and determined by the coefficient of outflow value.

The pathogens most commonly causing endophthalmitis are Staphylococcus aureus, Staph. epidermidis, Pseudomonas aeruginosa, Proteus mirabilis, indolepositive Proteus species, Escherichia coli, Klebsiella species, and Haemophilus influenzae. Ceftazidime is active against all these organisms. However, higher levels of antibiotic in the eye than those generally achieved by intravenous or intramuscular administration are required to eradicate certain ocular pathogens such as Staph. aureus and Staph. epidermidis."

After subconjunctival administration the concentration of ceftazidime achieved in the aqueous humour exceeds the MICs of not only pseudomonas, which is generally difficult to treat, but also most Staph. aureus and Staph. epidermidis. Nevertheless, in sight threatening infections of proved staphylococcal origin it may be more prudent to give an antistaphylococcal penicillin together with the subconjunctival ceftazidime.

The current choice of drugs in the prophylaxis and treatment of endophthalmitis includes an aminoglycoside. The subconjunctival use of gentamicin, either alone or in combination with another antibiotic, is common." Other aminoglycosides used subconjunctivally are framycetin " and tobramycin."' However, all aminoglycosides have varying degrees of ototoxicity and nephrotoxicity. Although a single subconjunctival dose of an aminoglycoside is unlikely to cause any significant toxicity, this difference could be important in the prolonged treatment of established serious ocular infections." Ceftazidime has a spectrum of activity similar to the aminoglycosides, but it has been shown to be free of the adverse reactions described above for aminoglycosides. Furthermore, many aminoglycoside resistant strains are sensitive to ceftazidime, ${ }^{12}$ and Davidson ${ }^{13}$ has stated that up to $30 \%$ of pseudomonas strains may be resistant to gentamicin.

One factor to be considered is the degree of local irritation resulting from a single subconjunctival injection. In this study subconjunctival ceftazidime did not cause any local irritation, nor were there any systemic side effects. Furthermore, none of the patients developed any postoperative infections.

In conclusion, this study shows that subconjunctival ceftazidime achieves high concentrations in the aqueous humour, indicating that the drug has a place in the prophylaxis and treatment of ophthalmic infections by the subconjunctival route.

Our thanks are due to Glaxo Group Rescarch for the estimation of aqueous and serum levels of ceftazidime.

\section{References}

1 O'Callaghan CH, Acred P, Harper PB, Ryan DM, Kirby SM. Harding SM. GR2()263, a new broad spectrum cephalosporin with antipscudomonal activity. Antimicrob Agents Chemother 1980; 17: 876-83

2 Phillips I, Warren C, Shannon K, King A. Hanslo D. Ceftazidime: in vitro antibacterial activity and susceptibility to Blactamases compared with that of cefotaxime. moxalactam and other B-Lactam antibiotics. J Antimicrob Chemother 1981; 8 (suppl B): 23-31.

3 Jones RN, Barry AL. Thornsberry C, et al. Ceftazidime, a pseudomonas-active cephalosporin: in vitro antimicrobial activity evaluation including recommendations for disc diffusion susceptibility tests. J Antimicroh Chemother 1981; 8 (suppl B): 187-211.

4 Walsted RA, Blika S. Penetration of ceftazidime into the normal rabbit and human eye. Scand J Infect Dis 1985; 44: 63-7.

5 Axclrod JL, Kochman RS, Horowicz MA, Youngworth L. Ceftazidime concentrations in human aquecous humor. Arch Ophthalmol 1984: 102: 923-5.

6 Giamarellou H. Kavouklis E. Grammatikou M. Daikos GK. Penetration of four B-lactam antibiotics with antipscudomenal activity into human aqueous humor. Curr Chemother Immunother 1982; 1: 153-5.

7 Barza M. Factors affecting the intra ocular penetration of antibiotics. Scand J Infect Dis 1978; 14: 151-9.

8 Lesar TS. Fiscella RG. Antimicrobial drug delivery to the eye. Drug Intell Clin Pharm 1985; 19: 642-54.

9 Forster RK, Abbott RL, Gelender H. Management of infectious endophthalmitis. Ophthalmology 1980; 87: 313-9.

10 Gorden TB. Cunningham RD. Tobramycin levels in aqueous humor after subconjunctival injection in humans. Am J Ophthalmol 1982; 93: 107-10.

11 Ainslie D. Henderson WG. Soframycin. Its penetration into the eye and its effect upon experimentally produced Staph. aureus and Ps. pyocyanea corneal infections. BrJ Ophthalmol 1958; 42: 513.

12 Harper PB. The in-vitro properties of ceftazidime. $J$ Antimicrob Chemother 1981;8 (suppl B): 5-13.

13 Davidson SI. Post-operative bacterial endophthalmitis. Trans Ophthalmol Soc UK 1985; 104: 278-84.

Accepted for publication 29 July 1986. 